\title{
TAS-303 Ameliorates Carbachol-Induced Detrusor Overactivity in Rats, Revealing Its Therapeutic Potential for Overactive Bladder ${ }^{\text {S }}$
}

\author{
Hiroya Mizutani, Fukumitsu Sakakibara, and Eiji Sasaki \\ Discovery and Preclinical Research Division, Taiho Pharmaceutical Co. Ltd., Tsukuba, Japan \\ Received December 12, 2019; accepted April 22, 2020
}

\begin{abstract}
Urinary incontinence is defined as an involuntary leakage of urine and is categorized into three types: stress urinary incontinence (SUI), urge urinary incontinence (UUI), and mixed urinary incontinence, which includes symptoms of SUI and UUI. As the underlying mechanisms of SUI and UUI are different, no drug is approved to treat all three types of urinary incontinence. TAS303 is a selective norepinephrine reuptake inhibitor and has therapeutic potential for patients with SUI. In this report, we describe newly discovered pharmacological properties of TAS303 and its effects on bladder function. Radioligand binding studies showed that TAS-303 inhibits M3 muscarinic receptor binding, with a Ki value of $547 \mathrm{nM}$. TAS-303 at 1,3 , and $10 \mathrm{mg} / \mathrm{kg}$ dose-dependently prolonged the intercontraction interval of carbachol-induced detrusor overactivity in rats, exhibiting a maximal effect that was comparable to tolterodine. These effects may result from coordinated regulation of bladder afferent activity via M3 muscarinic inhibition and $\beta 3$ adrenoreceptor activation by norepinephrine elevation due to norepinephrine
\end{abstract}

transporter inhibition. Moreover, TAS-303 at the effective dose for bladder function did not induce dry mouth or constipation in rats, showing that this compound may have a lower risk of antimuscarinic side effects. Thus, TAS-303 is expected to be a new profile agent with therapeutic potential for all types of urinary incontinence.

\section{SIGNIFICANCE STATEMENT}

Urinary incontinence is categorized into stress, urge, and mixed urinary incontinence, but because the underlying mechanisms of each differ, no drugs are available that treat all three. TAS-303 has therapeutic potential for stress urinary incontinence. This study describes newly discovered pharmacological properties of TAS-303, which ameliorated bladder afferent activity partly via M3 muscarinic inhibition, indicating improvement in urge urinary incontinence, and highlights the potential of TAS-303 as a new therapeutic agent for all types of urinary incontinence.

\section{Introduction}

Urinary incontinence is defined as an involuntary leakage of urine and may adversely affect social contacts and mental health (Sarkar and Ritch, 2000). Urinary incontinence is categorized into three types: urge urinary incontinence (UUI), stress urinary incontinence (SUI), and mixed urinary incontinence (MUI). SUI is characterized by involuntary leakage upon effort or exertion, or upon sneezing or coughing, and commonly occurs in adult women (Abrams et al., 2002). Damage to the muscles and nerves near the urethral sphincter after pregnancy and delivery is believed to cause impaired urethral resistance and promote SUI. For these reasons, the basic concept for SUI treatment is to increase urethral resistance. TAS-303, which is a selective norepinephrine reuptake inhibitor (NRI), was developed by Taiho Pharmaceutical Co. Ltd. and has therapeutic potential for patients with SUI (Mizutani et al., 2018). A phase II randomized clinical study in patients with SUI is being conducted.

The authors received no financial support for this research.

All authors declare that they have no competing financial interests.

https://doi.org/10.1124/jpet.119.264572.

S This article has supplemental material available at jpet.aspetjournals.org.
Overactive bladder $(\mathrm{OAB})$ is defined as urinary urgency, usually accompanied by frequency and nocturia, with or without UUI, in the absence of urinary tract infection or other obvious pathology (Haylen et al., 2010). UUI is characterized by a sudden desire to void, with involuntary voiding and leakage of significant amounts of urine, and is frequently caused by OAB. The prevalence of UUI is reported to be $15.3 \%$ (Plata et al., 2019). The prevalence of OAB is approximately $10.8 \%-43.1 \%$ and increases with age (Irwin et al., 2006; Coyne et al., 2011; Plata et al., 2019).

The symptoms of OAB have a negative impact on quality of life and may cause increased rates of depression and anxiety (Coyne et al., 2009). Additionally, patients with OAB, especially those with chronic comorbidities, experience a financial burden (Durden et al., 2018). Patients with urinary incontinence hesitate to go outdoors and avoid contact with others, which may result in social isolation.

In $\mathrm{OAB}$, activation of bladder afferent nerves is present, followed by the feeling of urgency and inappropriate triggering of detrusor muscle contraction. The underlying mechanism of $\mathrm{OAB}$ is considered to be abnormalities in bladder afferent signaling, which have been assumed to be caused by mechanisms based on myogenic, urotheliogenic, or other types of changes in the bladder (Peyronnet et al., 2019). In the

ABBREVIATIONS: MUI, mixed urinary incontinence; NET, norepinephrine transporter; NRI, norepinephrine reuptake inhibitor; OAB, overactive bladder; SUI, stress urinary incontinence; UUI, urge urinary incontinence. 
myogenic-related mechanism, denervation-related increased sensitivity to acetylcholine (denervation supersensitivity) alters the characteristics of smooth muscle, which induces local contraction of smooth muscle, so-called micromotions. These micromotions activate bladder afferent signals. Antimuscarinic agents may suppress micromotions, leading to reduced bladder afferent activity. Moreover, antimuscarinic agents are also suggested to directly suppress spontaneous detrusor contraction resulting from bladder afferent activation. In the urothelium-related mechanism, muscarinic receptors (M2 and M3), which are expressed in the urothelium and suburothelial myofibroblasts, are associated with bladder afferent activation. During bladder filling, $\beta 3$-adrenergic receptors are activated, which reduces bladder afferent activity and relaxes the detrusor muscle (Yamaguchi, 2013). In this context, antimuscarinic agents and $\beta 3$-adrenergic agonists as pharmacological treatments reduce episodes of UUI in patients in clinical trials and are approved for patients with OAB (Maman et al., 2014). Antimuscarinic agents have been the mainstay of drug therapy for a couple of decades because of their proven efficacy. However, these agents are often poorly tolerated because of side effects such as dry mouth and constipation, and patients often discontinue treatment.

Especially for patients with MUI, even if symptoms of one type of incontinence are reduced, the symptoms of the other type of incontinence remain, and patients' quality of life does not improve completely. Therefore, treating both types of incontinence is expected to improve the quality of life regarding urinary incontinence of MUI patients. No drug is approved to treat patients with MUI, because the underlying mechanisms of SUI and UUI are different. Thus, an agent that could treat both SUI and UUI is desired.

In this report, we show that in vitro, TAS-303 exhibited binding affinity to muscarinic M3 receptors, which are associated with bladder afferent activity. TAS-303 also antagonized carbachol-induced isolated bladder contraction ex vivo. TAS-303 showed a dose-dependent increase in the intercontraction interval in carbachol-induced detrusor overactivity model rats. Moreover, TAS-303 at the effective dose for bladder function did not induce dry mouth or constipation in rats.

\section{Materials and Methods}

Ethics Statement. All animal experiments were conducted according to the Guide for the Care and Use of Laboratory Animals, which is adopted and promulgated by the US National Institutes of Health and approved by the local Committee of Animal Use and Care of Taiho Pharmaceutical Co. Ltd. (Tsukuba, Japan). Sprague-Dawley rats (female, 11 to 12 weeks) (Charles River Japan, Kanagawa, Japan) were used for this study and housed in a controlled environment ( $24 \pm 1^{\circ} \mathrm{C}, 12$-hour light/dark cycle) with free access to food and water.

Chemicals. TAS-303 hydrochloride was synthesized by Taiho Pharmaceutical Co. Ltd. The chemical structure and pharmacological properties of TAS-303 were previously described (Mizutani et al., 2018). Atropine sulfate salt monohydrate, carbamoylcholine chloride (carbachol), and nisoxetine hydrochloride were purchased from Sigma-Aldrich Japan K.K. (Tokyo, Japan). Tolterodine tartrate was synthesized by Taiho Pharmaceutical Co. Ltd. SR59230A hydrochloride was purchased from Abcam plc. (Tokyo, Japan).

Receptor Binding. Dilutions of each test compound were made for concentrations ranging from 0.01 to $100 \mu \mathrm{M}$ for TAS-303 and 0.1 to $100 \mathrm{nM}$ for atropine. Each assay was conducted according to the protocols of Eurofins Pharma Discovery Services Taiwan Ltd. [Taipei, Taiwan (https://www.eurofinsdiscoveryservices.com/cms/cms-content/ services/in-vitro-assays/gpcrs/binding/: ITEM 252610, ITEM 252710, ITEM 252810, ITEM 252910, or ITEM 253010 for M1, M2, M3, M4, or M5 muscarinic receptor binding, respectively)]. CHO-K1 cells expressing human recombinant muscarinic receptors (M1, M2, M3, M4, or M5) were used for binding assays in assay buffer (50 mM Tris-HCl, $\mathrm{pH} 7.4$, $10 \mathrm{mM} \mathrm{MgCl} 2$, and $1 \mathrm{mM}$ EDTA). An 8- to $16-\mu \mathrm{g}$ aliquot of membrane was incubated with $0.8 \mathrm{nM}\left[{ }^{3} \mathrm{H}\right] N$-methylscopolamine for 120 minutes at $25^{\circ} \mathrm{C}$. Nonspecific binding was estimated in the presence of $1 \mu \mathrm{M}$ atropine. Membranes were filtered and washed three times in wash buffer (50 mM Tris-HCl, $\mathrm{pH} 7.4$ ), and the radioactivity on the filters was then counted to determine the specific binding of $\left[{ }^{3} \mathrm{H}\right]$ $\mathrm{N}$-methylscopolamine. All assays were performed in triplicate.

Measurement of Carbachol-Induced Isolated Bladder Contractions. Sprague-Dawley rats (female, 11 to 12 weeks) were euthanized by decapitation, and the bladder was isolated. The body of the bladder was used for preparation of the experimental strip. The bladder body was vertically cut into several strips and transferred into a $37^{\circ} \mathrm{C}$ organ bath $(10 \mathrm{ml})$ filled with Krebs-Henseleit solution (118 mM NaCl, $4.7 \mathrm{mM} \mathrm{KCl}, 2.5 \mathrm{mM}$ $\mathrm{CaCl}_{2}, 1.2 \mathrm{mM} \mathrm{KH}_{2} \mathrm{PO}_{4}, 25 \mathrm{mM} \mathrm{NaHCO}, 1.2 \mathrm{mM} \mathrm{MgSO}_{4}, 10 \mathrm{mM}$ glucose) saturated with $95 \% \mathrm{O}_{2}$ and $5 \% \mathrm{CO}_{2}$. One end of the strip was connected to an FD pickup transducer (TB-612T; Nihon Kohden Co., Ltd., Tokyo, Japan), and the other end was fastened to the organ bath. Tension of the bladder strip was recorded and analyzed using a PowerLab 16/30 (AD Instrument Pty Ltd., Sydney, Australia) via an FD pickup transducer and strain pressure amplifier (AP-601G; Nihon Kohden). The volume of test compound to be added was $100 \mu \mathrm{l}$. An appropriate volume of KrebsHenseleit solution was removed from the organ bath, and then the test compound solution was added. Carbachol solutions were then added cumulatively from the lowest concentration. The final concentration of carbachol solution was determined depending on the test compound and its concentration. For the contractile force, wave forms were analyzed on Chart v5.2.2 for Windows (PowerLab Chart v5.2.2; AD Instrument Pty Ltd.). The carbacholinduced maximum contractive response observed in the absence of compound (control) was designed as $100 \%$ contractile force and relative contractile force (\%) in the presence of compound at each concentration. The $\mathrm{EC}_{50}$ of carbachol was obtained from a sigmoidal curve with variable conditions at maximum effect. After calculation of $\mathrm{EC}_{50}, \mathrm{p} A_{2}$ was calculated on a Schild plot using three linear concentrations, and pharmacological responses were compared.

Cystometry. For evaluation of oral treatment, Sprague-Dawley rats (female, 11 weeks) were treated with $5 \mathrm{ml} / \mathrm{kg}$ ultrapure water or test compound (atropine, TAS-303, or tolterodine). Thirty minutes after administration, urethane solution was subcutaneously administered at a dose of $0.8 \mathrm{~g} / \mathrm{kg}$. Isoflurane anesthesia was introduced 15 minutes after urethane anesthesia. After that, isoflurane anesthesia was terminated, and the abdominal cavity was opened. A vinyl tube (SV45; Natsume Seisakusho Co., Ltd., Tokyo, Japan) was then inserted and indwelled in the bladder from the dome of the bladder. The other end of the catheter was connected to a three-way stopcock and divided two ways. One way was connected to a pressure transducer (DX-360; Nihon Kohden), and the other was connected to a syringe filled with physiologic saline or carbachol solution (1000 $\mu \mathrm{M})$ and connected to a continuous infusion device (KDS200; KD Scientific Inc., Holliston, MA). After catheterization, physiologic saline or carbachol solution was infused into the bladder at a rate of $3 \mathrm{ml} / \mathrm{h}$ via a microsyringe pump connected to the bladder. Intravesical pressure was measured using a pressure amplifier connected to a pressure transducer and recorded with a PowerLab 16/30 system. Wave forms indicating changes in intravesical pressure and urine weight were analyzed on Chart v5.2.2. The point when the changes in urine weight and intravesical pressure associated with urine excretion were observed was designated as the time of urination, and the time 
between two urination points was designated as an intercontraction interval. Considering the period of 15 minutes after initiation of cystometry as an acclimation period, intercontraction intervals observed during the subsequent 45-60 minutes were analyzed. For evaluation of intravenous treatment, physiologic saline or carbachol solution was infused. Considering the period of 60 minutes after initiation of cystometry as an acclimation period, intercontraction intervals observed during the subsequent 20 minutes after intravenous administration of test compound were analyzed.

Pilocarpine-Induced Salivation. This assay was performed according to the protocols of Nihon Bioresearch Inc. (Gifu, Japan). Briefly, Sprague-Dawley rats (female, 11 weeks) were orally treated with $5 \mathrm{ml} / \mathrm{kg}$ ultrapure water or test compound, and 30 minutes after administration, rats were anesthetized by intraperitoneal injection of urethane $(1.2 \mathrm{~g} / \mathrm{kg})$. Sixty minutes after administration of test compound, $1 \mathrm{mg} / \mathrm{kg}$ pilocarpine was intravenously administered via the tail vein, and saliva was collected for 60 minutes at 10 -minute intervals beginning just after administration.

Intestinal Transit with Charcoal Meal. This assay was performed according to the protocols of Nihon Bioresearch Inc. Briefly, test compound was orally administered to Sprague-Dawley rats (female, 11 weeks) after fasting for approximately 18 hours. Sixty minutes after administration, $5 \%$ charcoal suspension (w/v) was orally administered. Twenty minutes after charcoal administration, digestive tracts from the stomach to the cecum were extracted. The length of the entire intestine and the transport distance of the charcoal were measured, and the rate of charcoal transportation was calculated.

Statistical Analysis. Results are reported as means \pm S.D. All data analyses were conducted using SAS version 9.2 and EXSUS version 8.0.0 (CAC Exicare Corporation, Tokyo, Japan). Statistical analysis was carried out using the Student's $t$ test when the data were homogeneous or Aspin-Welch's $t$ test when the data were not homogeneous for two groups. One-way ANOVA followed by Dunnett's test or Steel's test was performed for multiple comparisons. A $5 \%$ significance level with these tests was considered to show statistical significance. To confirm the dose response, Williams' test was applied, and the significance level was set at $2.5 \%$ (one-sided).

\section{Results}

Inhibitory Activity of TAS-303 on Ligand Binding to Muscarinic Receptors. The potential of TAS-303 and atropine to inhibit ligand binding to muscarinic receptors (M1, M2, M3, M4, and M5) was assessed using cells expressing human recombinant muscarinic receptors. Atropine inhibited ligand binding of all muscarinic receptors, with a $\mathrm{Ki}$ value around $1 \mathrm{nM}$. Although TAS-303 also inhibited ligand binding of muscarinic receptors in a concentration-dependent manner, the inhibitory activity of TAS-303 on M3 muscarinic receptors was almost 1000-fold weaker than that of atropine. The rank of inhibitory potency was M3 = M5 $>$ M1 = M4 $>$ M2 (Table 1). The $\mathrm{IC}_{50}$ values of atropine and TAS-303 for muscarinic receptors are summarized in Table 2. Figure 1 shows inhibition curves for muscarinic receptors. Thus, TAS-303 mainly inhibited M3 and M5 receptors relative to the other muscarinic receptors, but its binding affinity was almost 1000 -fold lower than atropine.

Effect of TAS-303 on Carbachol-Induced Contraction of Isolated Rat Detrusor Smooth Muscle. In the organ bath experiments, the effect of TAS-303 on carbachol-induced contraction of isolated rat detrusor smooth muscle was evaluated to check the efficacy of TAS-303 (Fig. 2). To evaluate the reproducibility, carbachol-induced contraction curves on the same tissue were produced in the presence of vehicle. Five consecutive treatments with the vehicle showed no significant change in $\mathrm{EC}_{50}$ values. Increasing concentrations of atropine $(1,3,10$, and $30 \mathrm{nM})$ shifted the concentration-response curve to the right. The slope of Schild plots was 1.4 for atropine, and the $\mathrm{p} A_{2}$ value was calculated to be 8.4. These values were similar to those previously reported (Ikeda et al., 2002). Increasing concentrations of TAS-303 $(1,3,10$, and $30 \mu \mathrm{M})$ also caused a concentration-dependent rightward shift and produced a Schild slope of 0.78 and a $\mathrm{p} A_{2}$ value of 5.3. Therefore, TAS-303 antagonized the carbachol-induced contraction of isolated rat detrusor smooth muscle, but the required concentration was almost 1000 -fold higher compared with atropine. Treatment of bladder strips with TAS-303 reduced the carbachol-evoked maximum contraction at concentrations of $10 \mu \mathrm{M}$ or greater. We hypothesize that these responses are associated with inhibition of $\mathrm{Ca}^{2+}$ channels. Thus, we investigated the direct effect of TAS-303 on $\mathrm{Ca}^{2+}$ channels. TAS-303 exhibited affinity for L-type $\mathrm{Ca}^{2+}$ channels, and the $\mathrm{IC}_{50}$ value for this channel was $1.48 \mu \mathrm{M}$. Therefore, TAS-303 is considered to have a direct effect on L-type $\mathrm{Ca}^{2+}$ channels. In a separate experiment, the effect of TAS-303 on $\mathrm{KCl}(80 \mathrm{mM})$ solution-induced contraction of isolated rat bladder strips was evaluated. TAS-303, as well as the $\mathrm{Ca}^{2+}$ channel blocker, verapamil, suppressed $\mathrm{KCl}(80 \mathrm{mM})$ solution-induced contraction (data not shown).

Effect of TAS-303 on the Intercontraction Interval in Carbachol-Induced Detrusor Overactivity Model Rats. A previous study showed that intravesical instillation of carbachol simulates detrusor overactivity and reduces the intercontraction interval, and intravesical instillation of antimuscarinic agents suppresses carbachol-induced detrusor overactivity (Kim et al., 2005). This report suggests that the carbachol-induced detrusor overactivity model simulates the pathology of OAB. To evaluate the pharmacological potential of TAS-303 for regulating bladder overactivity in vivo, the intercontraction interval in carbachol-induced detrusor overactivity model rats after oral administration was measured (Fig. 3). The intercontraction interval after instillation of carbachol was $466 \pm 28$ seconds, which was significantly

TABLE 1

Inhibition of muscarinic receptor binding in vitro by TAS-303 and atropine.

The affinity of each compound was measured by inhibition of $\left[{ }^{3} \mathrm{H}\right] N$-methylscopolamine binding to muscarinic receptors. Ki values for receptor binding were determined from three independent experiments using seven drug concentrations.

\begin{tabular}{lccccc}
\hline & \multicolumn{5}{c}{ Muscarinic Receptor Binding } \\
\cline { 2 - 6 } Compound & \multicolumn{5}{c}{ Ki \pm S.D. } \\
\cline { 2 - 6 } & M1 & M2 & M3 & M4 & M5 \\
\cline { 2 - 6 } & $1.61 \pm 0.0833$ & $21.8 \pm 3.35$ & $0.547 \pm 0.0430$ & $1.60 \pm 0.115$ & $0.438 \pm 0.0327$ \\
TAS-303 $(\mu \mathrm{M})$ & $1.43 \pm 0.0808$ & $1.02 \pm 0.146$ & $0.417 \pm 0.0637$ & $0.594 \pm 0.145$ \\
\hline
\end{tabular}


TABLE 2

Inhibitory activities of TAS-303 and atropine on binding of $\left[{ }^{3} \mathrm{H}\right] N$-methylscopolamine to muscarinic receptors. $\mathrm{IC}_{50}$ values for each compound were measured by inhibition of $\left[{ }^{3} \mathrm{H}\right] N$-methylscopolamine binding to muscarinic receptors and were determined from three independent experiments using seven drug concentrations.

\begin{tabular}{|c|c|c|c|c|c|}
\hline \multirow{3}{*}{ Compound } & \multicolumn{5}{|c|}{ Muscarinic Receptor Binding } \\
\hline & \multicolumn{5}{|c|}{$\mathrm{IC}_{50} \pm \mathrm{S} . \mathrm{D}$} \\
\hline & M1 & M2 & M3 & M4 & M5 \\
\hline TAS-303 ( $\mu \mathrm{M})$ & $6.57 \pm 0.333$ & $52.0 \pm 7.95$ & $1.13 \pm 0.0862$ & $7.43 \pm 0.537$ & $0.707 \pm 0.0530$ \\
\hline Atropine (nM) & $1.42 \pm 0.148$ & $3.39 \pm 0.191$ & $2.11 \pm 0.304$ & $1.93 \pm 0.293$ & $0.959 \pm 0.232$ \\
\hline
\end{tabular}

lower than that in sham-operated rats $(786 \pm 62$ second, $P<$ 0.001 ), indicating successful establishment of the detrusor overactivity model. Oral administration of atropine $(10 \mathrm{mg} / \mathrm{kg})$ significantly increased the intercontraction interval by $57 \%$ compared with the vehicle group $(P<0.001)$. Oral administration of the muscarinic antagonist tolterodine $(0.3,1$, and $3 \mathrm{mg} / \mathrm{kg})$ dosedependently increased the intercontraction interval. At more than $1 \mathrm{mg} / \mathrm{kg}$ tolterodine, the intercontraction interval was significantly increased compared with the vehicle group $(P<$ 0.01 for $1 \mathrm{mg} / \mathrm{kg}, P<0.001$ for $3 \mathrm{mg} / \mathrm{kg}$ ) and was increased by $58 \%$ at a dose of $3 \mathrm{mg} / \mathrm{kg}$. Oral administration of TAS-303 (1, 3 , and $10 \mathrm{mg} / \mathrm{kg}$ ) also dose-dependently increased the intercontraction interval. At more than $3 \mathrm{mg} / \mathrm{kg}$ TAS-303, the intercontraction interval was significantly increased compared with the
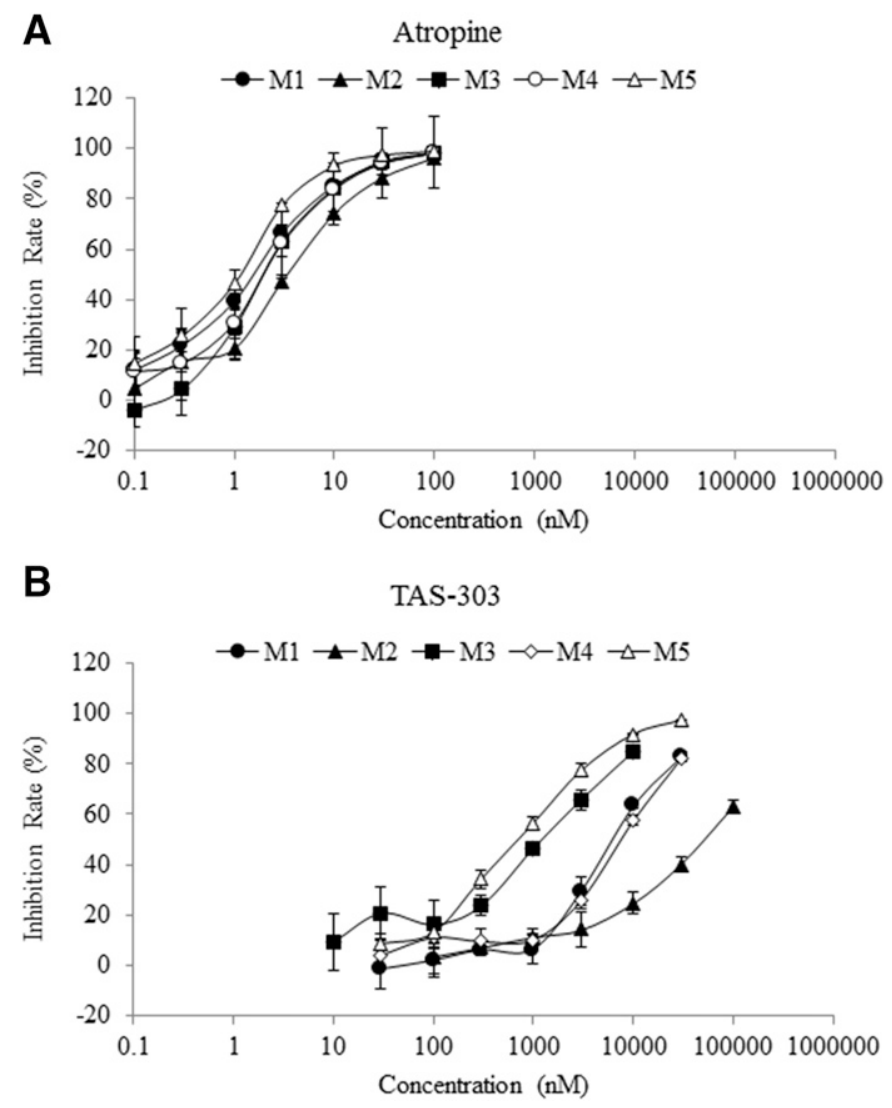

Fig. 1. Concentration-dependent inhibition of $\left[{ }^{3} \mathrm{H}\right] N$-methylscopolamine binding to muscarinic receptors (M1, M2, M3, M4, and M5) by (A) atropine and (B) TAS-303 at the indicated concentrations. The inhibition rate was determined from three independent experiments, and the data are expressed as the percent of control specific binding. Results are means \pm S.D. $(n=3)$. vehicle group $(P<0.01$ for $3 \mathrm{mg} / \mathrm{kg}, P<0.001$ for $10 \mathrm{mg} / \mathrm{kg}$ ) and was increased by $58 \%$ at a dose of $10 \mathrm{mg} / \mathrm{kg}$. The micturition volume and bladder capacity, but not micturition pressure, improved after administration of TAS-303 in a dose-dependent manner compared with the vehicle group (Supplemental Fig. 1).

Combination Effect of Low-Dose Atropine and Nisoxetine on the Intercontraction Interval in Carbachol-Induced Detrusor Overactivity Model Rats. TAS-303 increased the intercontraction interval in detrusor overactivity model rats at $3 \mathrm{mg} / \mathrm{kg}$. The maximum drug concentration $(49.5 \mathrm{nM})$ of TAS-303 was below the $\mathrm{IC}_{50}$ of in vitro ligand binding inhibition of M3 receptors $(1.13 \mu \mathrm{M})$ (Table 2; Mizutani et al., 2018). Therefore, a mechanism of action in addition to inhibition of M3 receptors was considered to underlie the increase in the intercontraction interval after administration of TAS-303. The $\beta 3$-adrenergic receptor agonist mirabegron, an approved drug for $\mathrm{OAB}$, decreases afferent activity from the bladder in rats with arterial endothelial injury, and as a consequence, the intercontraction interval and bladder capacity increase (Sawada et al., 2013). Thus, we hypothesized that the increase in norepinephrine caused by inhibition of norepinephrine reuptake by TAS-303 via $\beta 3$ adrenergic receptors may contribute to the increase in the intercontraction interval. Effects of the combination of lowdose atropine and the NRI nisoxetine on the intercontraction interval of carbachol-induced detrusor overactivity model rats were assessed to clarify whether a synergistic effect of the two agents was present. A previous report showed that intravenous injection of atropine $(100 \mu \mathrm{g} / \mathrm{kg})$ causes a change in cystometric parameters, including the intercontraction interval, in rats with bladder hyperactivity (Takeda et al., 2002). Thus, the doses of atropine for these experiments were set at $0.3,1,3$, and $10 \mu \mathrm{g} / \mathrm{kg}$ to assess the effect of low-dose atropine. Administration of five consecutive intravenous doses of vehicle produced no remarkable change in the intercontraction interval (data not shown), and nisoxetine $(1 \mathrm{mg} / \mathrm{kg})$ also produced no remarkable change in the intercontraction interval (Fig. 4). In the presence of nisoxetine, cumulative intravenous administration of low-dose atropine $(0.3,1,3,10 \mu \mathrm{g} / \mathrm{kg})$ increased the intercontraction interval in a dose-dependent manner compared with pretreatment $(P<0.01)$. In contrast, no change was seen in the absence of nisoxetine. The intercontraction interval (\%) after administration of both atropine $(10 \mu \mathrm{g} / \mathrm{kg})$ and nisoxetine was $151 \% \pm 16 \%$ and was significantly higher than that of only atropine $(10 \mu \mathrm{g} / \mathrm{kg})(104 \% \pm 12 \%, P<0.05)$. No statistically significant differences between the intercontraction interval values before administration of agents were found. 

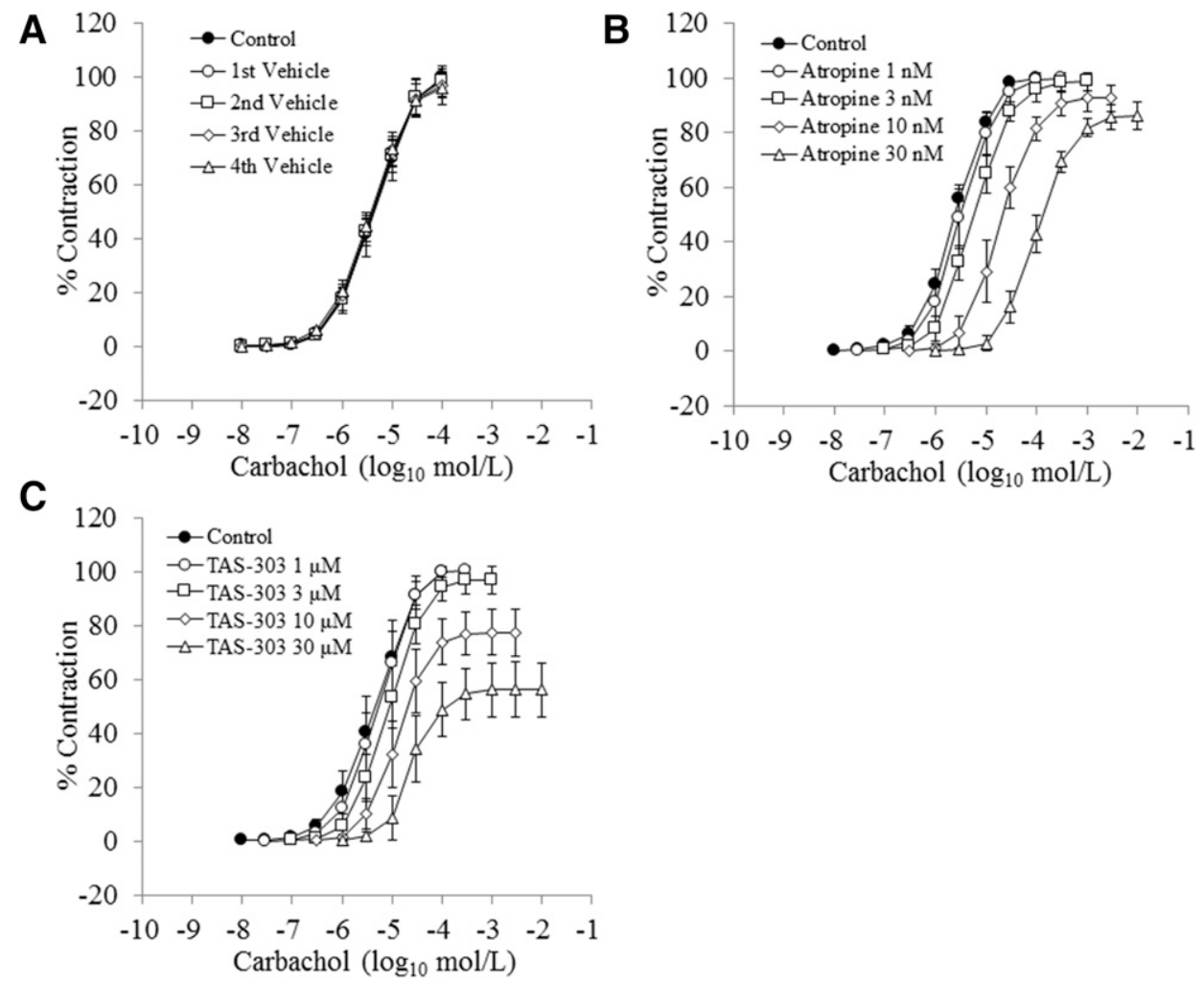

Effect of a $\beta 3$-Adrenergic Receptor Antagonist on the TAS-303-Induced Increase in the Intercontraction Interval in Carbachol-Induced Detrusor Overactivity Model Rats. To investigate the involvement of $\beta 3$-adrenergic receptors in the TAS-303-induced increase in the intercontraction interval, the effect of the $\beta 3$-adrenergic receptor antagonist SR59230A on the intercontraction interval was measured (Fig. 5). Intravenous administration of SR59230A $(0.3 \mathrm{mg} / \mathrm{kg})$ alone caused no apparent changes in the intercontraction interval. Intravenous administration of SR59230A ( 0.1 and $0.3 \mathrm{mg} / \mathrm{kg})$ decreased the TAS-303-induced increase in the intercontraction interval in a dose-dependent manner. The intercontraction interval was significantly decreased at $0.3 \mathrm{mg} / \mathrm{kg}$ SR59230A $(P<0.01)$ in the presence of TAS-303.

Effect of TAS-303 on Pilocarpine-Induced Salivation in Rats. Treatment with muscarinic antagonists reduces the amount of salivation induced by pilocarpine in rats (Byeon et al., 2017). To estimate the risk of dry mouth caused by antagonistic activity on muscarinic receptors, the effect of TAS-303 on pilocarpine-induced salivary secretion was examined (Fig. 6). Oral administration of atropine $(10 \mathrm{mg} / \mathrm{kg})$ significantly suppressed pilocarpine-induced salivary secretion by $98 \%$ compared with the vehicle group $(P<0.001)$. Oral administration of tolterodine $(1,3,10$, and $30 \mathrm{mg} / \mathrm{kg})$ resulted in a dose-dependent decrease in salivary secretion. At 10 and $30 \mathrm{mg} / \mathrm{kg}$ tolterodine, salivary secretion was significantly decreased compared with the vehicle group by $80 \%$ and $96 \%$, respectively $(P<0.001)$. In contrast, oral administration $(3,10$, and $30 \mathrm{mg} / \mathrm{kg}$ ) of TAS-303 resulted in no change in salivary secretion. At $100 \mathrm{mg} / \mathrm{kg}$ TAS-303, salivary secretion was significantly decreased by $29 \%$ compared with the vehicle group $(P<0.05)$.
Effect of TAS-303 on Intestinal Transit of Charcoal Meal in Rats. Muscarinic antagonists induce constipation. A previous report showed that muscarinic antagonists, including tolterodine, produce a dose-dependent decrease in small intestine transit (McNamara et al., 2009). To estimate the risk of TAS-303 to induce constipation, the effect of TAS-303 on intestinal charcoal transit was examined (Fig. 7). Intestinal transit was expressed as a percentage of the length at which charcoal traveled the total length of the colon. Oral administration of atropine $(10 \mathrm{mg} / \mathrm{kg})$ significantly suppressed intestinal transit to $41 \% \pm 3 \%$ compared with the vehicle group $(71 \% \pm 3 \%, P<0.001)$. Oral administration of tolterodine $(30 \mathrm{mg} / \mathrm{kg})$ resulted in a significant decrease in intestinal transit $(58 \% \pm 4 \%, P<0.05)$. In contrast, TAS-303 at each dose exhibited no significant change in intestinal transit compared with the vehicle group.

\section{Discussion}

TAS-303 was created as an NRI, and clinical trials of this agent for patients with SUI are being conducted. In this paper, newly discovered pharmacological profiles of TAS-303 regarding antimuscarinic effects were evaluated. Moreover, we estimated the risk of antimuscarinic side effects of TAS-303. These studies demonstrated that TAS-303 has therapeutic potential for UUI with better safety and tolerability profiles compared with the current antimuscarinic agents.

We evaluated the direct effect of TAS-303 on receptors, ion channels, and enzymes that are involved in bladder contraction or bladder afferent activity. TAS-303-mediated $(10 \mu \mathrm{M})$ inhibition of ligand binding to adrenergic receptors, prostaglandin receptors, purinergic receptors, and tachykinin receptors was under $50 \%$ for each type of receptor. Moreover, 


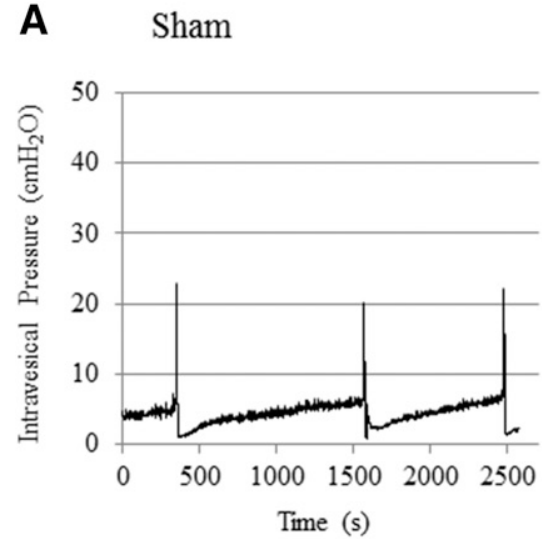

D

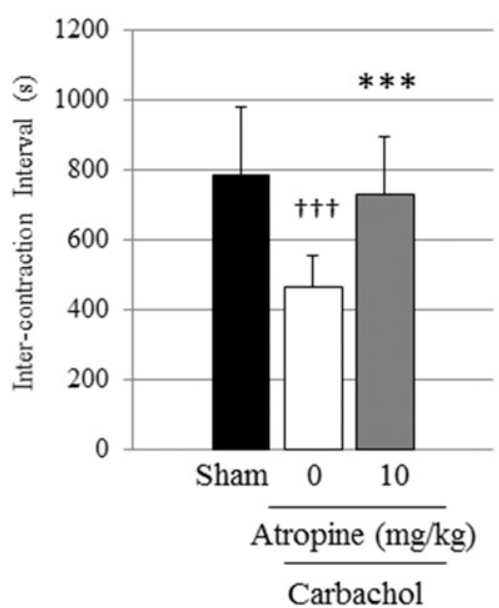

B Carbachol (Vehicle)

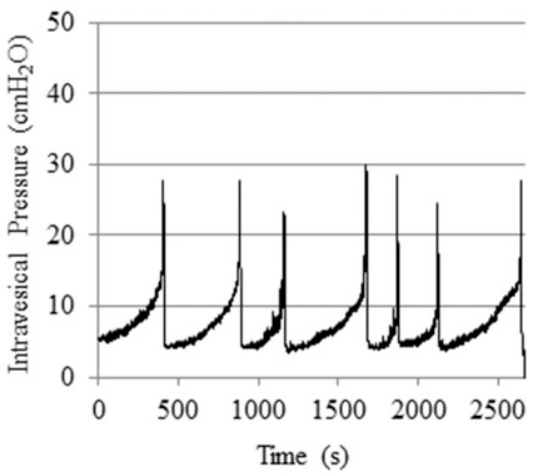

E

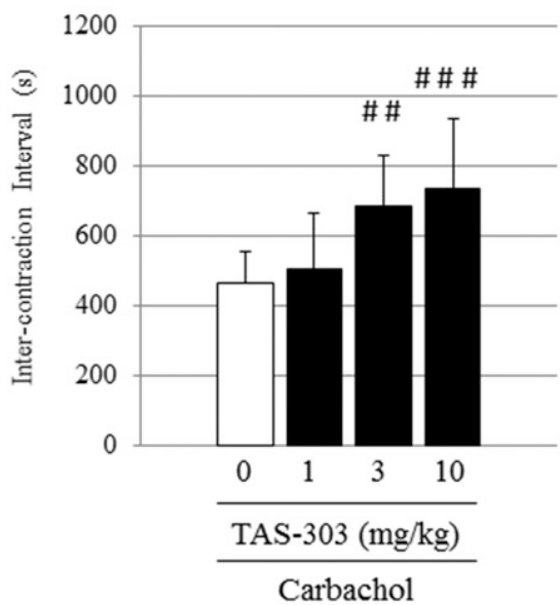

C Carbachol (TAS-303 $10 \mathrm{mg} / \mathrm{kg}$ )

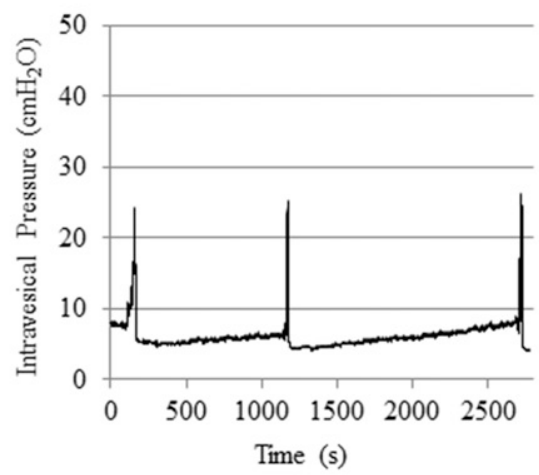

$\mathbf{F}$

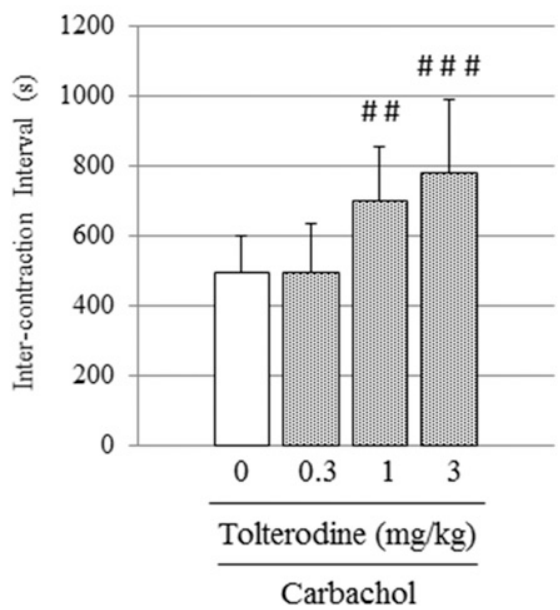

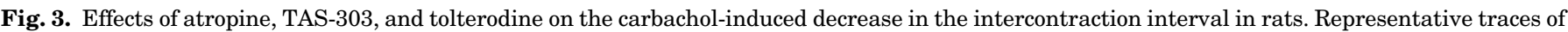

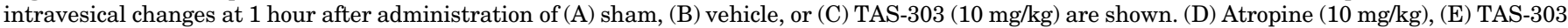

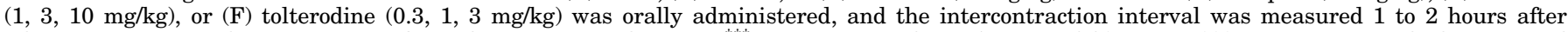

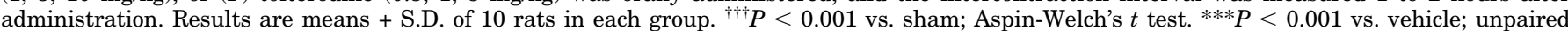
Student's $t$ test. ${ }^{\# \#} P<0.005$; ${ }^{\# \# \# ~} P<0.0005$ vs. vehicle; Williams' test.

the percent agonistic activity of TAS-303 (10 $\mu \mathrm{M})$ on phosphodiesterase, nitric oxide synthase, and $\mathrm{K}_{\mathrm{ATP}}$ channels was under 50\%. Therefore, TAS-303 is demonstrated to have almost no direct effect on these receptors, ion channels, and enzymes (data not shown).

In $\mathrm{OAB}$, activation of bladder afferent nerves is present, leading to urgency as well as spontaneous detrusor contraction. The mechanisms of $\mathrm{OAB}$ are associated with bladder afferent activation, the causes of which are considered to be mainly myogenic or urotheliogenic changes (Peyronnet et al., 2019). In the former mechanism, denervation supersensitivity induces micromotions and then stimulates bladder afferent activity. In the latter mechanism, bladder afferent nerves are activated by binding of urothelium-derived acetylcholine to M2 and M3 receptors and binding of ATP to purinergic P2X receptors (Yoshida et al., 2006; Lips et al., 2007). Previous reports have suggested that muscarinic receptor antagonists may depress the bladder afferent nerves in some animal models (Yokoyama et al., 2005; De Laet et al., 2006; Iijima et al., 2007). Therefore, antimuscarinic agents may suppress afferent nerve activation by inhibiting the receptors through the myogenic or urotheliogenic mechanism. Moreover, antimuscarinic agents are also suggested to directly suppress spontaneous detrusor contraction. In this study, oral administration of the muscarinic receptor antagonist, tolterodine, suppressed carbachol-induced detrusor overactivity in rats. TAS-303 (3 mg/kg) also prolonged the intercontraction interval in this model, and the maximum drug concentration (49 $\mathrm{nM}$ ) was below its potency $\left(\mathrm{IC}_{50} 1.13 \mu \mathrm{M}\right)$ to inhibit ligand binding in vitro. This concentration in plasma likely suppresses M3 receptors by about $20 \%$, suggesting incomplete suppression of the intercontraction interval with inhibition of M3 receptors only. Therefore, additional mechanisms of action other than M3 inhibition likely contribute to the prolongation of the intercontraction interval.

Previous reports showed that $\beta 3$ adrenoreceptors are indirectly or directly involved in inhibition of bladder afferent activation. B3 adrenoreceptor agonists bind to receptors that are expressed in the urothelium, inducing the release of nitric oxide. Nitric oxide then inhibits bladder afferent nerve activation (Andersson and Persson, 1995; Birder et al., 2002). In addition, activation of $\beta 3$ adrenoreceptors themselves directly inhibits bladder afferent activity in rats (Aizawa et al., 2012; Hatanaka et al., 2013; Sawada et al., 2013). Furthermore, $\beta 3$ adrenoreceptor agonists also produce concentration-dependent relaxation of resting tension and 


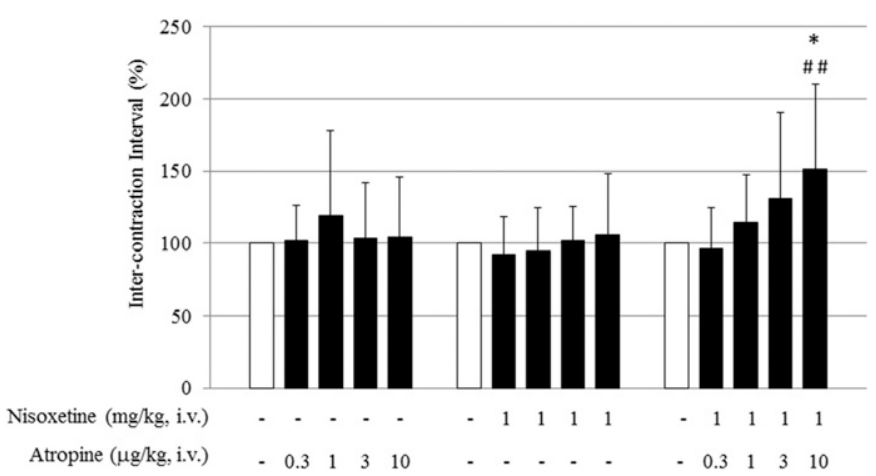

Fig. 4. Effects of combination therapy with atropine and nisoxetine on the intercontraction interval after intravesical installation of carbachol in rats. Atropine $(0.3,1,3,10 \mu \mathrm{g} / \mathrm{kg})$ or nisoxetine $(1 \mathrm{mg} / \mathrm{kg})$ was intravenously administered in a cumulative manner. The intercontraction interval was measured during the subsequent 20 minutes after intravenous administration. The intercontraction interval observed prior to administration with the compound was designated as $100 \%$. Results are means + S.D. of $8-13$ rats in each group. $* P<0.05$ vs. atropine $(10 \mu \mathrm{g} / \mathrm{kg})$; unpaired Student's $t$ test. ${ }^{\# \#} P<0.005$ vs. pretreatment with both compounds; Williams' test.

inhibit carbachol-induced contraction of isolated detrusor strips from humans and rats (Kanie et al., 2012; Svalø et al., 2013). Regarding NRIs, tomexetine augments norepinephrine-mediated relaxation of carbachol-induced bladder contraction, the effect of which is related to $\beta$ adrenoreceptors (Foreman and McNulty, 1993). Therefore, $\beta 3$ adrenoreceptor activation may suppress bladder afferent activation and spontaneous detrusor contraction. Moreover, activation of $\beta 3$ adrenoreceptors decreases nerve-derived acetylcholine release in human and rat bladder (D' Agostino et al., 2015; Silva et al., 2017). These reports suggest that M3 receptors and $\beta 3$ adrenoreceptors coordinately regulate the bladder afferents. We previously reported that the concentration of norepinephrine in plasma after TAS303 administration is elevated in rats (Mizutani et al., 2018). Thus, we hypothesized that norepinephrine elevation due to inhibition of the norepinephrine transporter (NET) may contribute to suppression of bladder afferents via $\beta 3$ adrenoreceptors. To test this hypothesis, we investigated the effect of a combination of a low dose of atropine and the NRI nisoxetine, neither of which affects the intercontraction interval alone. The combination of both agents prolonged the intercontraction interval in rats. This finding supports the hypothesis that inhibition of NET is an underlying mechanism of TAS-303 activity. Norepinephrine binds to three subtypes of $\beta$ adrenoreceptors $(\beta 1, \beta 2$, and $\beta 3)$ and appears to be substantially more potent at the $\beta 1$ than the $\beta 2$ receptor (Emorine et al., 1989; Insel, 1996). These receptors are expressed in the rat bladder. The rank order of potency for the relaxation response is CL316243 $(\beta 3$ agonist $)=\operatorname{procaterol}(\beta 2$ agonist $)>$ dobutamine ( $\beta 1$ agonist) in the rat bladder (Takeda et al., 2003; Uchida et al., 2005), suggesting that norepinephrine relaxes the bladder mainly through $\beta 3$ adrenoreceptors in rats. Prolongation of the intercontraction interval after administration of TAS-303 was blocked by treatment with a $\beta 3$ adrenoreceptor antagonist. A previous report showed that the combination of solifenacin, an M3 muscarinic receptor antagonist, and mirabegron, a $\beta 3$ adrenoreceptor agonist, synergistically inhibits cold stress-induced detrusor overactivity in spontaneously hypertensive rats (Imamura et al., 2017). The combination of oxybutynin and mirabegron at concentrations that show

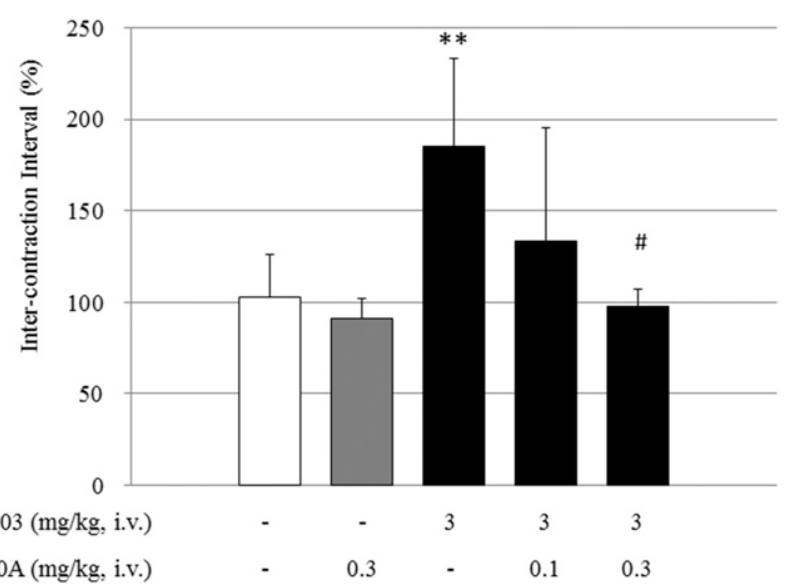

Fig. 5. Dose-response effect of SR59230A on extension of the intercontraction interval by TAS-303 in carbachol-treated rats. SR59230A $(0.1$ or $0.3 \mathrm{mg} / \mathrm{kg}$ ) was intravenously coadministered with TAS-303 (3 mg/kg). The intercontraction interval was measured during the subsequent 20 minutes after intravenous administration. The intercontraction interval observed prior to administration of the compound was designated as $100 \%$. Results are means + S.D. of four to five rats in each group. $* * P<0.01$ vs. vehicle; unpaired Student's $t$ test. ${ }^{\#} P<0.025$ vs. TAS-303 $(3 \mathrm{mg} / \mathrm{kg})$ in the absence of SR59230A; Williams' test.

almost no effect as monotherapies significantly improves cystometric parameters such as bladder capacity in spinal cord-injured rats (Wada et al., 2017). These reports are consistent with our hypothesis. Expression of $\beta$ adrenoreceptor $(\beta 1, \beta 2$, and $\beta 3)$ mRNA has also been confirmed in human bladder at rates of $1.5 \%, 1.4 \%$, and $97 \%$, respectively (Nomiya and Yamaguchi, 2003). Furthermore, functional studies using human bladder muscle strips have proposed that $\beta 3$ adrenoreceptors are the predominant subtype for the relaxation response (Wuest et al., 2009). The distribution of M3 muscarinic receptors and $\beta 3$ adrenoreceptors in human bladder tissues overlaps (Tyagi et al., 2006; Bschleipfer et al., 2007; Otsuka et al., 2013). Combination treatment with solifenacin and mirabegron for $\mathrm{OAB}$ symptoms provides better efficacy than each monotherapy and is well tolerated over 12 months

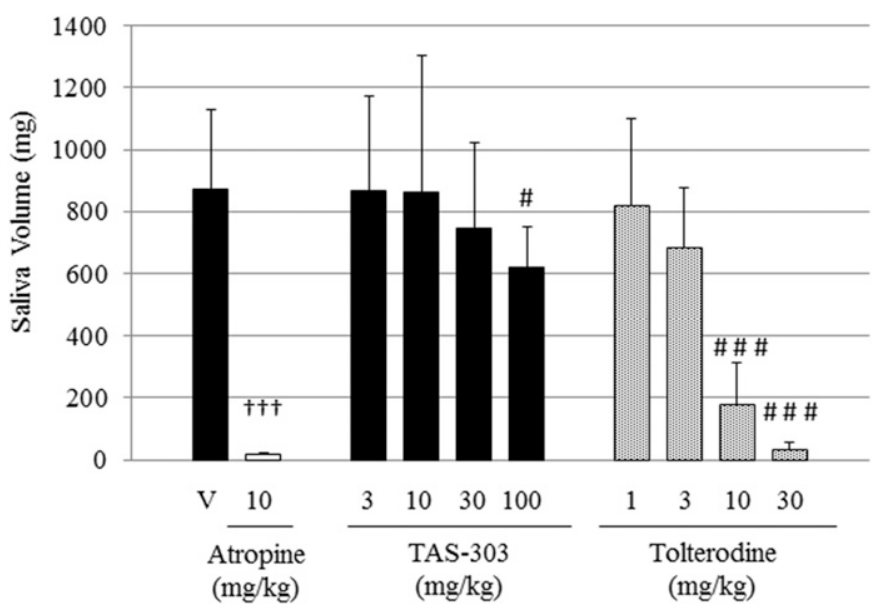

Fig. 6. Effects of atropine, TAS-303, and tolterodine on salivary secretion in rats. Saliva was collected for 60 minutes at 1 hour after oral administration of vehicle (V), atropine $(10 \mathrm{mg} / \mathrm{kg})$, TAS-303 $(3,10,30$, $100 \mathrm{mg} / \mathrm{kg})$, or tolterodine $(1,3,10,30 \mathrm{mg} / \mathrm{kg})$. Results are means + S.D. of 12 rats in each group. ${ }^{\dagger} P<0.001$ vs. vehicle; Aspin-Welch's $t$ test. ${ }^{\#} P<0.05 ;{ }^{\# \# \#} P<0.001$ vs. vehicle; Steel's multicomparison test. 


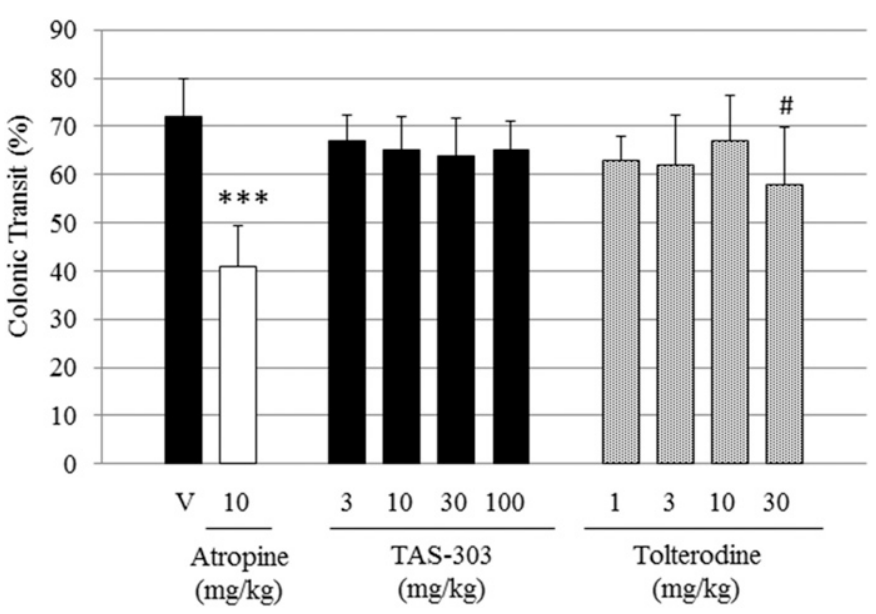

Fig. 7. Effects of atropine, TAS-303, and tolterodine on intestinal transit in rats. Measurement of charcoal transportation was conducted at 1 hour after oral administration of vehicle (V), atropine (10 mg/kg), TAS-303 (3, $10,30,100 \mathrm{mg} / \mathrm{kg})$, or tolterodine $(1,3,10,30 \mathrm{mg} / \mathrm{kg})$. Intestinal transit (\%) is expressed as a percentage of the length at which charcoal traveled to the total length of the colon. Results are means + S.D. of eight rats in each group. ${ }^{* * *} P<0.001$ vs. vehicle; unpaired Student's $t$ test. ${ }^{\#} P<0.05$ vs. vehicle; Dunnett's multicomparison test.

(Gratzke et al., 2018). This combination therapy has been approved by the Food and Drug Administration. Based on these findings, TAS-303 may exert two effects (M3 antagonism and $\beta 3$ agonism by norepinephrine elevation through NET inhibition) and suppress bladder afferent activation or spontaneous detrusor contraction, implying improvement in $\mathrm{OAB}$ symptoms in the clinical setting.

Antimuscarinic agents are widely used for the treatment of OAB. However, these agents lead to various adverse events due to antimuscarinic effects, including constipation, dry mouth, and residual urine (Yamaguchi, 2013). These agents are associated with a significantly higher risk of discontinuation due to adverse events than placebo, and the risk of discontinuation tends to be reduced by lowering the dose (Chapple et al., 2008). Combination therapy with mirabegron and solifenacin significantly ameliorates the symptoms of $\mathrm{OAB}$ with no significant additional adverse events compared with monotherapy or placebo (Abrams et al., 2015). These findings suggest that the weaker antimuscarinic effect may reduce the risk of the well known adverse events, and the additional mechanism on $\beta 3$-adrenoceptors is also expected to not cause serious adverse effects.

In this report, effects of TAS-303 to induce dry mouth and constipation would be observed at a higher dose than that used to affect bladder function, with dissociation margins of approximately 30 times and more than 100 times, respectively. With respect to dry mouth in particular, norepinephrine promotes salivation by activating $\alpha 1$ adrenoreceptors (Bobyock and Chernick, 1989). Therefore, norepinephrine elevation through inhibition of norepinephrine uptake by TAS-303 may counteract suppression of salivary secretion due to an antimuscarinic effect.

Cardiovascular system side effects caused by $\beta$ adrenoreceptors may occur because $\beta$ adrenoreceptors are expressed in the cardiovascular system or vascular smooth muscle (Brodde and Michel, 1999; Skeberdis et al., 2008). Clinical trials in patients with $\mathrm{OAB}$ with mirabegron have previously demonstrated no evidence of increased cardiovascular risk over placebo (White et al., 2018). However, most clinical trials of $\beta 3$ adrenoreceptor agonists for patients with $\mathrm{OAB}$ excluded those with serious cardiovascular morbidities (Andersson, 2017). Furthermore, a previous study reported that a history of cardiovascular dysfunction may predispose patients to these side effects (Balachandran and Duckett, 2015). Recently, a double-blind, single-dose, placebo-controlled crossover study of TAS-303 at a dose of $18 \mathrm{mg}$ was conducted in 16 patients with SUI. No reports of important safety findings, including changes in ECG or blood pressure, were noted in this clinical trial (Yono et al., 2017). This finding suggests that this compound was well tolerated.

TAS-303, a selective NET inhibitor, is expected to be effective in patients with SUI. Currently, a double-blind, randomized, placebo-controlled phase II trial of TAS-303 in female patients with SUI is being conducted. In addition, TAS-303 is expected to be effective against UUI because this compound prolonged the intercontraction interval in carbachol-induced detrusor overactivity model rats. TAS-303 at an effective dose for bladder function did not induce dry mouth or constipation in rats, indicating that this agent will likely have a lesser risk of antimuscarinic side effects. As no drug has been approved for the treatment of both SUI and UUI, TAS-303 is expected to be a new agent with therapeutic potential and an acceptable safety profile.

\section{Acknowledgments}

The authors thank Atsushi Hakozaki for providing support in writing this manuscript.

\section{Authorship Contributions}

Participated in research design: Mizutani, Sakakibara, Sasaki. Conducted experiments: Mizutani, Sakakibara.

Performed data analysis: Mizutani, Sakakibara.

Wrote or contributed to the writing of the manuscript: Mizutani, Sakakibara.

\section{References}

Abrams P, Cardozo L, Fall M, Griffiths D, Rosier P, Ulmsten U, van Kerrebroeck P, Victor A, and Wein A; Standardisation Sub-committee of the International Continence Society (2002) The standardisation of terminology of lower urinary tract function: report from the Standardisation Sub-committee of the International Continence Society. Neurourol Urodyn 21:167-178.

Abrams P, Kelleher C, Staskin D, Rechberger T, Kay R, Martina R, Newgreen D, Paireddy A, van Maanen R, and Ridder A (2015) Combination treatment with mirabegron and solifenacin in patients with overactive bladder: efficacy and safety results from a randomised, double-blind, dose-ranging, phase 2 study (Symphony). Eur Urol 67:577-588.

Aizawa N, Homma Y, and Igawa Y (2012) Effects of mirabegron, a novel $\beta 3$ adrenoceptor agonist, on primary bladder afferent activity and bladder microcontractions in rats compared with the effects of oxybutynin. Eur Urol 62: 1165-1173

Andersson KE (2017) Pharmacology: cardiovascular effects of mirabegron. Nat Rev Urol 14:587-588.

Andersson KE and Persson K (1995) Nitric oxide synthase and the lower urinary tract: possible implications for physiology and pathophysiology. Scand J Urol Nephrol Suppl 175:43-53.

Balachandran AA and Duckett JR (2015) The risk and severity of developing symptomatic palpitations when prescribed mirabegron for overactive bladder. Eur J Obstet Gynecol Reprod Biol 187:60-63.

Birder LA, Nealen ML, Kiss S, de Groat WC, Caterina MJ, Wang E, Apodaca G, and Kanai AJ (2002) Beta-adrenoceptor agonists stimulate endothelial nitric oxide synthase in rat urinary bladder urothelial cells. J Neurosci 22:8063-8070.

Bobyock E and Chernick WS (1989) Vasoactive intestinal peptide interacts with alpha-adrenergic-, cholinergic-, and substance-P-mediated responses in rat parotid and submandibular glands. J Dent Res 68:1489-1494.

Brodde OE and Michel MC (1999) Adrenergic and muscarinic receptors in the human heart. Pharmacol Rev 51:651-690.

Bschleipfer T, Schukowski K, Weidner W, Grando SA, Schwantes U, Kummer W, and Lips KS (2007) Expression and distribution of cholinergic receptors in the human urothelium. Life Sci 80:2303-2307.

Byeon JY, Kim YH, Kim SH, Lee CM, Choi CI, Bae JW, Jang CG, Lee SY, and Lee YJ (2017) Inhibition of salivary secretion by tolterodine transdermal patch. Arch Pharm Res 40:1455-1463. 
Chapple CR, Khullar V, Gabriel Z, Muston D, Bitoun CE, and Weinstein D (2008) The effects of antimuscarinic treatments in overactive bladder: an update of a systematic review and meta-analysis. Eur Urol 54:543-562.

Coyne KS, Sexton CC, Vats V, Thompson C, Kopp ZS, and Milsom I (2011) National community prevalence of overactive bladder in the United States stratified by sex and age. Urology 77:1081-1087.

Coyne KS, Wein AJ, Tubaro A, Sexton CC, Thompson CL, Kopp ZS, and Aiyer LP (2009) The burden of lower urinary tract symptoms: evaluating the effect of LUTS on health-related quality of life, anxiety and depression: EpiLUTS. BJU Int 103 (Suppl 3):4-11.

D'Agostino G, Maria Condino A, and Calvi P (2015) Involvement of $\beta 3$-adrenoceptors in the inhibitory control of cholinergic activity in human bladder: direct evidence by $[(3) \mathrm{H}]$-acetylcholine release experiments in the isolated detrusor. Eur J Pharmacol 758:115-122.

De Laet K, De Wachter S, and Wyndaele JJ (2006) Systemic oxybutynin decrease afferent activity of the pelvic nerve of the rat: new insights into the working mechanism of antimuscarinics. Neurourol Urodyn 25:156-161.

Durden E, Walker D, Gray S, Fowler R, Juneau P, and Gooch K (2018) The economic burden of overactive bladder (OAB) and its effects on the costs associated with other chronic, age-related comorbidities in the United States. Neurourol Urodyn 37:1641-1649.

Emorine LJ, Marullo S, Briend-Sutren MM, Patey G, Tate K, Delavier-Klutchko C, and Strosberg $\mathrm{AD}$ (1989) Molecular characterization of the human beta 3 adrenergic receptor. Science $\mathbf{2 4 5}$ :1118-1121.

Foreman MM and McNulty AM (1993) Alterations in $\mathrm{K}(+)$-evoked release of $3 \mathrm{H}-$ norepinephrine and contractile responses in urethral and bladder tissues induced by norepinephrine reuptake inhibition. Life Sci 53:193-200.

Gratzke C, van Maanen R, Chapple C, Abrams P, Herschorn S, Robinson D, Ridder A, Stoelzel M, Paireddy A, Yoon SJ, et al. (2018) Long-term safety and efficacy of mirabegron and solifenacin in combination compared with monotherapy in patients with overactive bladder: a randomised, multicentre phase 3 study (SYNERGY II). Eur Urol 74:501-509.

Hatanaka T, Ukai M, Watanabe M, Someya A, Ohtake A, Suzuki M, Ueshima K, Sato S, and Kaku S (2013) Effect of mirabegron, a novel $\beta 3$-adrenoceptor agonist, on bladder function during storage phase in rats. Naunyn Schmiedebergs Arch Pharmacol 386:71-78.

Haylen BT, de Ridder D, Freeman RM, Swift SE, Berghmans B, Lee J, Monga A Petri E, Rizk DE, Sand PK, et al.; International Urogynecological Association; International Continence Society (2010) An International Urogynecological Association (IUGA)/International Continence Society (ICS) joint report on the terminology for female pelvic floor dysfunction. Neurourol Urodyn 29:4-20.

Iijima K, De Wachter S, and Wyndaele JJ (2007) Effects of the M3 receptor selective muscarinic antagonist darifenacin on bladder afferent activity of the rat pelvic nerve. Eur Urol 52:842-847.

Ikeda K, Kobayashi S, Suzuki M, Miyata K, Takeuchi M, Yamada T, and Honda K (2002) $\mathrm{M}(3)$ receptor antagonism by the novel antimuscarinic agent solifenacin in the urinary bladder and salivary gland. Naunyn Schmiedebergs Arch Pharmacol 366:97-103.

Imamura T, Ogawa T, Minagawa T, Nagai T, Suzuki T, Saito T, Yokoyama H, Nakazawa M, and Ishizuka O (2017) Combined treatment with a $\beta_{3}$-adrenergic receptor agonist and a muscarinic receptor antagonist inhibits detrusor overactivity induced by cold stress in spontaneously hypertensive rats. Neurourol Urodyn 36:1026-1033.

Insel PA (1996) Seminars in medicine of the Beth Israel Hospital, Boston. Adrenergic receptors--evolving concepts and clinical implications. $N \mathrm{Engl} \mathrm{J} \mathrm{Med}$ 334:580-585.

Irwin DE, Milsom I, Hunskaar S, Reilly K, Kopp Z, Herschorn S, Coyne K, Kelleher C, Hampel C, Artibani W, et al. (2006) Population-based survey of urinary incontinence, overactive bladder, and other lower urinary tract symptoms in five countries: results of the EPIC study. Eur Urol 50:1306-1314, NaN-1315.

Kanie S, Otsuka A, Yoshikawa S, Morimoto T, Hareyama N, Okazaki S, Kobayashi R, Hasebe K, Nakao K, Hayashi R, et al. (2012) Pharmacological effect of TRK-380, a novel selective human $\beta 3$-adrenoceptor agonist, on mammalian detrusor strips. Urology 79:744.e1-744.e7.

Kim Y, Yoshimura N, Masuda H, de Miguel F, and Chancellor MB (2005) Antimuscarinic agents exhibit local inhibitory effects on muscarinic receptors in bladder-afferent pathways. Urology 65:238-242.

Lips KS, Wunsch J, Zarghooni S, Bschleipfer T, Schukowski K, Weidner W, Wessler I, Schwantes U, Koepsell H, and Kummer W (2007) Acetylcholine and molecular components of its synthesis and release machinery in the urothelium. Eur Urol $\mathbf{5 1}$ 1042-1053.

Maman K, Aballea S, Nazir J, Desroziers K, Neine ME, Siddiqui E, Odeyemi I, and Hakimi Z (2014) Comparative efficacy and safety of medical treatments for the management of overactive bladder: a systematic literature review and mixed treatment comparison. Eur Urol 65:755-765.

McNamara A, Pulido-Rios MT, Sweazey S, Obedencio GP, Thibodeaux H, Renner T, Armstrong SR, Steinfeld T, Hughes AD, Wilson RD, et al. (2009) Pharmacological properties of TD-6301, a novel bladder selective muscarinic receptor antagonist. Eur J Pharmacol 605:145-152.
Mizutani H, Sakakibara F, Komuro M, and Sasaki E (2018) TAS-303, a novel selective norepinephrine reuptake inhibitor that increases urethral pressure in rats, indicating its potential as a therapeutic agent for stress urinary incontinence. $J$ Pharmacol Exp Ther 366:322-331.

Nomiya M and Yamaguchi O (2003) A quantitative analysis of mRNA expression of alpha 1 and beta-adrenoceptor subtypes and their functional roles in human normal and obstructed bladders. J Urol 170:649-653.

Otsuka A, Kawasaki H, Matsumoto R, Shinbo H, Kurita Y, Iwashita T, and Ozono S (2013) Expression of $\beta$-adrenoceptor subtypes in urothelium, interstitial cells and detrusor of the human urinary bladder. Low Urin Tract Symptoms 5:173-180.

Peyronnet B, Mironska E, Chapple C, Cardozo L, Oelke M, Dmochowski R, Amarenco G, Gamé X, Kirby R, Van Der Aa F, et al. (2019) A comprehensive review of overactive bladder pathophysiology: on the way to tailored treatment. Eur Urol $\mathbf{7 5}$ : 988-1000.

Plata M, Bravo-Balado A, Robledo D, Trujillo CG, Caicedo JI, Cataño JG, Arenas J, Rondón M, and Londoño D (2019) Prevalence of lower urinary tract symptoms and overactive bladder in men and women over 18 years old: the Colombian overactive bladder and lower urinary tract symptoms (COBaLT) study. Neurourol Urodyn $\mathbf{3 8}$ : 200-207.

Sarkar PK and Ritch AE (2000) Management of urinary incontinence. J Clin Pharm Ther 25:251-263.

Sawada N, Nomiya M, Hood B, Koslov D, Zarifpour M, and Andersson KE (2013) Protective effect of a $\beta 3$-adrenoceptor agonist on bladder function in a rat model of chronic bladder ischemia. Eur Urol 64:664-671.

Silva I, Costa AF, Moreira S, Ferreirinha F, Magalhães-Cardoso MT, Calejo I, SilvaRamos M, and Correia-de-Sá P (2017) Inhibition of cholinergic neurotransmission by $\beta_{3}$-adrenoceptors depends on adenosine release and $\mathrm{A}_{1}$-receptor activation in human and rat urinary bladders. Am J Physiol Renal Physiol 313:F388-F403.

Skeberdis VA, Gendviliene V, Zablockaite D, Treinys R, Macianskiene R, Bogdelis A, Jurevicius J, and Fischmeister R (2008) beta3-adrenergic receptor activation increases human atrial tissue contractility and stimulates the L-type $\mathrm{Ca}^{2+}$ current. $J$ Clin Invest 118:3219-3227.

Svalø J, Nordling J, Bouchelouche K, Andersson KE, Korstanje C, and Bouchelouche P (2013) The novel $\beta 3$-adrenoceptor agonist mirabegron reduces carbachol-induced contractile activity in detrusor tissue from patients with bladder outflow obstruction with or without detrusor overactivity. Eur J Pharmacol 699:101-105.

Takeda H, Matsuzawa A, Igawa Y, Yamazaki Y, Kaidoh K, Akahane S, Kojima M, Miyata H, Akahane M, and Nishizawa O (2003) Functional characterization of beta-adrenoceptor subtypes in the canine and rat lower urinary tract. $J$ Urol 170: $654-658$.

Takeda H, Yamazaki Y, Igawa Y, Kaidoh K, Akahane S, Miyata H, Nishizawa O, Akahane M, and Andersson KE (2002) Effects of beta(3)-adrenoceptor stimulation on prostaglandin $\mathrm{E}(2)$-induced bladder hyperactivity and on the cardiovascular system in conscious rats. Neurourol Urodyn 21:558-565.

Tyagi S, Tyagi P, Van-le S, Yoshimura N, Chancellor MB, and de Miguel F (2006) Qualitative and quantitative expression profile of muscarinic receptors in human urothelium and detrusor. $J$ Urol 176:1673-1678.

Uchida H, Shishido K, Nomiya M, and Yamaguchi O (2005) Involvement of cyclic AMP-dependent and -independent mechanisms in the relaxation of rat detrusor muscle via beta-adrenoceptors. Eur J Pharmacol 518:195-202.

Wada N, Shimizu T, Takai S, Shimizu N, Tyagi P, Kakizaki H, and Yoshimura N (2017) Combinational effects of muscarinic receptor inhibition and $\beta 3$-adrenoceptor stimulation on neurogenic bladder dysfunction in rats with spinal cord injury. Neurourol Urodyn 36:1039-1045.

White WB, Siddiqui E, Tat T, Franks B, and Schermer CR (2018) Cardiovascular safety of mirabegron: analysis of an integrated clinical trial database of patients with overactive bladder syndrome. J Am Soc Hypertens 12:768-778.e1.

Wuest M, Eichhorn B, Grimm MO, Wirth MP, Ravens U, and Kaumann AJ (2009) Catecholamines relax detrusor through beta 2 -adrenoceptors in mouse and beta 3 adrenoceptors in man. J Pharmacol Exp Ther 328:213-222.

Yamaguchi O (2013) Latest treatment for lower urinary tract dysfunction: therapeutic agents and mechanism of action. Int J Urol 20:28-39.

Yokoyama O, Yusup A, Miwa Y, Oyama N, Aoki Y, and Akino H (2005) Effects of tolterodine on an overactive bladder depend on suppression of C-fiber bladder afferent activity in rats. $J$ Urol 174:2032-2036.

Yono M, Kimura M, Inoue Y, Furukawa K, Ito K, Tsuruya K, Nagaoka M, Hoashi K and Irie S (2017) A double-blind, placebo-controlled clinical pharmacological study of TAS-303 in female patients with stress urinary incontinence, in Proceedings of ICS 2017; 2017 September 12-15; Florence, Italy, pp A382, The International Continence Society, Bristol, UK.

Yoshida M, Inadome A, Maeda Y, Satoji Y, Masunaga K, Sugiyama Y, and Murakami $\mathrm{S}$ (2006) Non-neuronal cholinergic system in human bladder urothelium. Urology 67:425-430.

Address correspondence to: Hiroya Mizutani, Discovery and Preclinical Research Division, Taiho Pharmaceutical Co. Ltd., 3 Okubo, Tsukuba, Ibaraki 300-2611, Japan. E-mail: hiro-mizutani@taiho.co.jp 